Article

\title{
CRITICAL PERSPECTIVES ON INDIGENOUS RESEARCH
}

\author{
GEORGE J. SEFA DEI \\ [Nana Sefa Atweneboah I] \\ Humanities, Social Sciences and Social Justice Education \\ OISE, University of Toronto
}

\begin{abstract}
Keywords
Co-existence, dialogic encounter, indigeneity, Indigenous research, social science
\end{abstract}

\section{Biographical note}

George Sefa Dei is Professor at the Department of Sociology and Equity Studies, Ontario Institute for Studies in Education of the University of Toronto. Professor Dei's teaching and research interests are in the areas of anti-racism, minority schooling, international development and anti-colonial thought. $\mathrm{He}$ is the author, co-author, and editor of several books on anti-racism and education, including Anti-Racism Education: Theory and Practice; Hardships and Survival in Rural West Africa; Reconstructing 'Drop-Out': A Critical Ethnography of the Dynamics of Black Students' Disengagement from School and Indigenous Knowledge in Global Contexts. He may be reached at gdei@oise.utoronto.ca

\section{Acknowledgments}

I want to thank Min Kaur of the Department of Humanities, Social Sciences and Social Justice Education of the Ontario Institute for Studies in Education of the University of Toronto for reading, commenting and strengthening an earlier draft of the paper.

Research does not exist outside of place nor outside of history. Thus, I begin by recognizing the Indigenous Peoples of Turtle Island, now known as the continent of North America, on whose Land I stand today. As a scholar of African descent my Indigenousness is lived in cultural memory and in my body. I share my Indigeneity with others on whose Land I have chosen to settle. At the same time, by choosing to settle on Turtle Island I recognize I have also become complicit in the White colonialist/settler occupation of other peoples' land. Other perspectives I bring to this discussion come from my intellectual and political position as a sociologist with a critical questioning 
mind informed by my solidarity with other Indigenous peoples. Therefore, I see my scholarship and politics as incomplete if such work does not further a project of questioning the occupation of "Stolen Lands". To this end I want to push the edges of the intellectual envelope and troublesome taken for granted assumptions that guide much of social science research. Throughout this text I take up Indigeneity as an identity, a part of myself that I can take for granted because of my rootedness in Indigenous social relations and places. At the same time - and somewhat paradoxically - Indigeneity is a process of coming to a specifically Indigenous consciousness.

\section{Social Research and 'Unquestioned Answers'}

I recall a conversation very long ago with a colleague who argued that 'research' is "alien" to Indigenous peoples given the colonial history of dominant social science research. Historically, dominant social science research has been parasitic, in the literal sense that normal social scientific practices have siphoned off Indigenous knowledges, without contributing to the survival or wellbeing of Indigenous peoples. Indeed, scientific 'research' has used Indigenous peoples as 'guinea pigs' in the furtherance of the development of Western [social] science disciplines, up to and including murderous 'experiments' on Indigenous peoples. ${ }^{1}$ At the time, I argued strenuously that despite this, research is not a monopoly of Western 'science'; rather research is something that all peoples can lay claim to and that all peoples may use. I have not changed my thoughts on this and still support the potential for social science, including social science by and for Indigenous peoples. However, increasingly I have become wary of social science research and its colonial impositions. Hence, I have wondered if my friend was right, after all? Recently, in a graduate class on 'Frantz Fanon and Decolonization: Pedagogical Challenges' at the Ontario Institute for Studies in Education of the University of Toronto, a doctoral student of mine, Rainos Mutumba reiterated a similar critique of 'academic research' arguing that academic research is so thoroughly compromised by its entanglements with colonialism that it is fundamentally incompatible with Indigenous communities and their priorities.

To ground the sources of the contention we should first ask: what is [social] research? I see research as an investigation, as a search for knowledge and as a variety of ways to communicate such knowledge to others in the spirit of shared understandings of our worlds and mutual co-existence. If we accept this operational definition of research that I am putting forward here, then it stands to reason that research has always been a central part of all existence and that the passing on of knowledge in communities constitutes a research activity. Defined in this way, it becomes clear that from time

\footnotetext{
${ }^{1}$ The notorious case of the sex workers in the Majengo, Nairobi slums, who have been 'studied' for decades for their resistance to HIV, without any meaningful improvements in their lives, is just one example.
} 
immemorial Indigenous Peoples have done research: they have studied, analyzed, interpreted and communicated their cultural and natural surroundings to themselves and to others. Their methods of knowledge, however, are quite different from mainstream colonial research. Dominant approaches to social science are just one way of doing research but certainly not the 'only' way.

In his book Research is Ceremony (2008), Cree scholar Shawn Wilson speaks of research as being all about unanswered questions but also a process of revealing our unquestioned answers. Wilson also posits that an Indigenous paradigm of research holds true to principles of relationality and of relational accountability (p. 6). By this, he means that ideas develop through relations we have with others, including kin, and that in our research we are accountable to those with whom we have relationships. Indeed, Wilson argues that our ideas only make sense within the context of our relations, maintaining that '(a)n idea cannot be taken out of this relational context and still maintain its shape' (p. 8). Thus, Wilson maintains that relationality is a major difference between conventional 'academic'/Western research and Indigenous research. In Indigenous research, he argues the emphasis is not on rules and abstractions, but on building relationships, for example through storytelling, that allows for the sharing of life experiences. In this relational view, knowledge cannot be ethical unless it helps create positive changes in the lives of research participants. With Wilson, I would argue that this relational approach is research too: a way of searching and of coming to know, but grounded in resolutely Indigenous worldviews.

\section{The Indigenous Research Agenda}

This paper sets out to tease out some of the parameters of Indigenous research. I do not focus so much on the methodological approach to Indigenous research. I am more interested in a philosophical or conceptual discussion of what Indigenous research is or is not. I maintain that Indigenous research is different from mainstream colonial/Western science research. I also reiterate unapologetically that the days of Non-Indigenous peoples becoming 'experts' on Indigenous peoples are long over. Everywhere Indigenous scholars and researchers are resisting and writing from and for their own communities. In the discussion I bring my own personal and scholarly perspectives on Indigenous research, the aims, scopes, practices that I see as most critical. A key argument I hope to convey is that that Indigenous research is just one aspect of a much broader, transformative project of Indigenous resistance (and decolonization) in all spheres of life.

Indigenous research has a particular research agenda. Indigenous research (like anti-colonial and anti-racist research) has a specific political and academic goal to subvert the dominant ideology that seeks to dismiss, downplay and decenter the importance and relevance of local peoples knowing in everyday practice (see Dei and Johal, 2005). A 
critical Indigenous research methodology must explore how the subjects of study resist continuous colonizing relations and practices, including many of the 'normal' practices of social science. Research must explore the nature and extent of the popular forms of consciousness that inform Indigenous resistances and the local peoples' interpretations of everyday practice and experiences. In this way, Indigenous researchers challenge the dominant approach of researching Indigenous people for 'data', an oppressive practice that transforms Indigenous peoples into research 'objects' to be 'mined' by the researcher. Indigenous researchers argue that Indigenous peoples lives cannot be pursued as research 'content', so that they become mere descriptive appendages to theoretical formulations. Instead, research must recognize the ways Indigenous peoples themselves make and create knowledge.

It is important to reiterate from the onset that I am not calling for doing away entirely with Western science knowledge and research. For one thing we can't: coexistence of knowledge already exists in our communities. The issue then becomes how we deal with the dilemmas of this co-existence. As Andreotti, Ahenakew and Cooper (2011) have argued, in other contexts, as Indigenous researchers/scholars if we are to present Indigenous knowings/research as "too different' we risk being interpreted as making "no sense" and therefore not worthy of "knowledge/research practice" (p. 45). Or, if these knowledges/research practices are presented as very similar to dominant ways of knowing/research, then Indigenous knowledges/research can be perceived as having no value and/or not adding anything new nor significant to Eurocentric or colonial knowledge and research.

Another issue that arises is the nature of the co-existence of Western and Indigenous knowledges. Are we talking about parallel bodies of knowledge, and if so, how do we challenge the dominance of Western humanist ideologies and research practices that tend to devalue other bodies of thought and local communities? Or are we interested in producing a new synthesis that would rupture power relations of knowledge production in the Western academy? How is this to be practically accomplished given the risk of the asymmetrical assimilation of Indigenous knowledges into Eurocentric research practices? Yet another challenge of negotiating the co-existence of Western and Indigenous research is that in the Western academy we are constantly asked to separate our scholarship from our political activism. But as Indigenous researchers we do not stand apart from our local communities. After all, our communities help sustain us in the brutal world of the Western academy and its colonial satellites all over the world.

Ultimately, I would argue that Indigenous research is a complex decolonized approach of producing, interrogating, validating and disseminating knowledge based on Indigenous peoples' cosmology/worldview or 'worldsense' [Oyewumi, 1997]. Indigenous research is rooted in diverse Indigenous values system that bring with them their own unique methodological and theoretical framework, accepted by an epistemic community of Indigenous peoples (and not only 'certified' Indigenous scholars). Yet in arguing that 
Indigenous research is part of on-going colonial resistance other key questions arise. For example, what constitutes research in Indigenous communities? How do our epistemologies and conceptual frameworks engage questions of politics and embodiment? What do we see as the moral, ethical, spiritual and cosmological dimensions of producing knowledge about Indigenous peoples and their communities? In all this, there is a danger of epistemic insularity that must be replaced with epistemic openness. This is not only true of Indigenous research; to expand the explanatory power of the science of research, we must subvert the ethnocentrism of Western science's research as a lens to interrogate Indigenous communities and the Indigenous human condition (see Dei, 2011).

\section{Indigenous Research as Healing}

We must challenge the one trick pony of Western research methodologies. For contemporary research on and in Indigenous communities, we must interrogate issues that are specifically excluded from dominant Eurocentric approaches to research. These include questions of how we bring emotional attachment and embodiment to the subject of our pursuit; how our research becomes relevant to our communities and not just to our academies and to the demands of publication linked to professional advancement; how we rethink communities in research collaboration and how we engage local communities in our work as key and equal partners in research. Raising these questions is part of the broader commitment to strengthening local peoples' capacities to undertake their own research.

The question of embodiment in Indigenous research is more than understanding knowledge as socially and discursively constructed and it is more than a plea not to intellectually distance ourselves from the knowledge we produce. Embodiment in Indigenous research is also about "sentient perceptions and the search for symbiotic relationship between physical, mental, emotional and spiritual experiences" (Batacharya, 2010). Taken this way, research becomes a way to connect to our physical, social, emotional and spiritual selves. Apart from placing embodiment in a social dynamics and context of research, there must also be a recognition that embodiment hurts. When we conduct research we implicate our bodies in taking responsibility for the knowledge we produce. Thus research holds possibilities for spiritual and physical wounding. The understanding of embodiment in Indigenous research therefore should touch on healing. Put another way, for the colonized and oppressed, Indigenous research can and must be a healing process. It is an approach to study and understand ourselves and our communities, including to understanding and healing pain resulting from colonial relations. 


\section{Indigenous Research as a Dialogic Encounter}

As Wilson emphasizes, Indigenous research seeks a relational status with our communities in the search for knowledge. Local peoples are seen as legitimate coproducers of knowledge, in ways not typically recognized in Western research with its emphasis on the exclusive expertise of the certified researcher. Moreover, Indigenous research is aimed at sustaining local peoples' capacity to undertake their own research, under their own terms and rules of engagement. It is about building human capacities in local communities. In this way, Indigenous research asks: how do we co-produce knowledge with our communities in ways that fundamentally shift the established ways of knowledge production? In other words, how can Indigenous research challenge Western ways of knowing, including within the social sciences?

In practice, challenging dominant ways of knowledge production involves critical dialogues among multiple parties - a sort of 'dialogic encounter' with an 'epistemic community'. Elsewhere (Dei, 1999) I have defined the "epistemic community" as scholars and community workers with shared intellectual leanings and a shared commitment to equity and social justice. This includes both Indigenous and non-Indigenous researchers. This epistemic space is a place for researchers and learners to openly utilize the body, mind, spirit and soul interface in critical dialogues about understanding their communities. It is also a space that nurtures conversations that acknowledges the importance and implications of working with a knowledge base about the society, culture, and nature nexus. Among other things, this epistemic space considers nature - the land, water and our relations with non-human species - as a vital part of knowledge production and knowledge sharing. Such spaces can only be created when we open our minds broadly to reimagine research as a site and opportunity to challenge dominant paradigms and academic reasoning (see Dei, 2013a).

With regards to decolonizing research in the academy, the two key areas of recent focus are: developing Indigenous methodologies for the study of a phenomenon and developing research protocols with Indigenous peoples and communities. We know Maori researchers have already taken significant leads on these two fronts in their own communities. We must search for ways of affirming and validating a wide range of such Indigenous methodological approaches in the (Western) academy. At a minimum, this means recognizing that research is not a one-way conversation. Indigenous research seeks to establish relationships between researcher and local peoples by developing a high degree of trust as a priority to ensure openness, honesty and integrity. It places emphasis on establishing true rapport with subjects in order to generate meaningful field data. This is meant to ensure that the researcher is not the sole and sovereign arbiter deciding whether data is meaningful or not - the meaningfulness of findings is the outcome of a relationship and ongoing conversation between the researcher and Indigenous 
communities. Practically, this means that short-term research relationships are eschewed in favour of strong lasting and responsible relationships with respondents.

Regarding developing research protocols with Indigenous communities, the emphasis is on how we maintain ethics and the integrity of a research process or what Wilson (2008) refers to as axiology - the ethics or morals that guide the search for knowledge and judge which information is worthy of searching for. Axiology also concerns itself with how that knowledge is gained and asks: "What part of this reality is worth finding out more about?" "What is ethical to do in order to gain this knowledge and what will this knowledge be used for?" (Wilson 2008, p. 34). Our approach to scientific research should be in meaningful power-sharing partnership with local communities, upholding our responsibilities to local communities and addressing questions of academic responsibility and social expectations on the part of the academic researcher. Indigenous research protocols relate to the conduct of the actual research, including ways of gaining entry into local communities, what is research on, how research information is gathered and used and who has final control and ownership of the research process.

\section{The Transformative Potential of Indigenous Research}

Indigenous research questions the problematic of veiled neutrality and asks about the transformative potential of social research. Radebe (2012) rightly notes that "colonial discourses continue to permeate knowledge production... [and] despite [Indigenous and minority bodies] increasing representation in academic scholarship," research in the arts, humanities and the social and natural sciences are dominated by non-Indigenous protocols and researchers who are assigned discursive and ethnographic authority on Indigenous communities (see also Harding, 2004; Smith, 1997; Smith, 1993; Swigonski, 1993; Longino, 1993 in related contexts). Mainstream research continues to speak as if it were 'universal' while embodying the priorities and concerns, but also the ways of knowing, of those in relatively powerful social locations. But this claim to universality can no longer be sustained. We know that a researcher's social location, including race, ethnicity, gender, class, sexuality and age are far from irrelevant to research, whether done by the powerful or by those in relatively dominated social locations. Social locations offer particular knowledges that are relevant to and do influence the conduct and interpretations of research (Dei and Johal 2005, Litowitz, 2009; Khan, 2005; Loutzenhesier, 2007). Practically, this means that white male 'experts' can no longer speak as if from places of universal authority; while Indigenous researchers and their unique insights must be newly appreciated for what they can bring to a transformed social science, especially when it comes to explaining and describing Indigenous experience. 
For many of us doing critical anti-racist, anti-colonial and Indigenous research we have come to realize that there are obvious limitations in the ability of traditional or conventional social research paradigms and methods to capture and explain the experiences of Indigenous, minoritized, colonized and oppressed peoples. To counter and redress these limitations the primary focus in Indigenous research methodology ought to be on the experiences of the Indigenous, colonized and oppressed subjects as key to understanding issues of Indigeneity, oppressions and the pursuit of transformative praxis (see Smith, 1999). Indigenous research works with the "epistemic saliency" (i.e., acknowledging the relevance, authenticity and primacy of local claims of knowing) of marginalized voices in accounting for their own experiences of oppression and colonization. Such epistemic saliency refers to the authenticity of local subject voice but not in the sense of purity or a voice uncontaminated. Rather, it rests on the important recognition of the centrality of such voice in a researcher coming to know and understand the lived experiences of the researched. Indigenous research foregrounds such voice, as well as the personal, experiential and a political subject in search for social change. But Indigenous research does not take a "romanticized view" of subject voices, and neither does it exclude research participants from participating in theory building, data analysis and interpretation (Loutzenheriser, 2007; p. 15).

Local peoples' narratives are well-woven together with theoretical explorations in Indigenous research. In effect, Indigenous research foregrounds local participants/peoples' voices in research, rather than subordinating their contributions to the researcher's analysis and the literature. Indigenous research places the self, subjectivity at the centre of social analysis, and subjectivity is viewed as an important site of knowing and learning. Indigenous research reflects on research as a personal and a political journey. Indigenous research embraces the idea of community and common destiny and research becomes a recovery of one's humanity, personhood and spirit. In effect Indigenous research is about making the material, physical and spiritual connection in the search for knowledge through social research.

\section{Indigenous Research as Life-Changing Ceremony}

In understanding research as colonial or Indigenous, it is important to put the matter of scholarly research in a broader context. There are some fundamental questions to be asked regarding the conditions and the socio-political contexts for research; what are the forces behind the push for social research; what type of research is being done and how, and to what intents and purposes? Indigenous research is about heralding such questions, including: what does it mean to develop a research culture in the Western academy and for a faculty to develop a research profile? Within the academy, so-called 'scholarly research' has always been pursued in a competitive landscape and for the most 
part is driven more by needs of the market than the interest of the communities under study. Indigenous research demands that Western-based and Western-trained academics and researchers begin to rethink the what, when, how and why of social research. Indigenous research is driven foremost by the interests of the local communities being researched rather than the interests of the academic disciplines of the researcher of the corporate funders of the research being undertaken. What this means is that questions of the relevance of knowledge and research are and should always be at the forefront of a researcher's intellectual pursuits. Similarly, Indigenous research aims at transformation as an end goal. This research seeks to transform communities rather than maintaining the existing order of things. This calls for research to always examine the exercise of power and the ways asymmetrical power relations structure a given community and the subject of study. Indigenous research is thus in many ways about domination studies from an anti-colonial perspective.

Indigenous research continues research as a sacred activity or as ceremony, a "raising of consciousness," as positioned by Wilson (2008). He goes on to assert that "Indigenous research is a life changing ceremony" (Wilson, 2008, p. 61). The sacredness of research activity associated with local research rests on the connection between the physical and metaphysical realms of social existence and how knowledge about the human condition connects issues of spirituality, Land teachings and the reverence of Mother Earth. Research in Indigenous communities cannot proceed without the spiritual blessing of the ancestors and Mother Earth. Research activity then is accorded a reverence given the blessing of Elders, ancestors and the cultural custodians in local communities. As Wilson (2001) claims, as a researcher "you are answering to all your relations when you are doing research" (p. 177). The central place of the spiritual and spirituality in research serves to distinguish dominant/colonial [social] research from Indigenous research. Dominant research resting on the trappings of a limited understanding of science tends to dismiss the spiritual as anti-intellectual and not knowledge. Conventional [social science] research is still struggling to study and engage spirituality in knowledge production and social science research methodologies are yet to be appropriately engaged to fully comprehend the place of spirituality in human lives.

Indigenous research also raises questions about intellectual property differently. It is not so much about who own the knowledge or field data as how is due recognition given to local subjects as the producers of knowledge gained. Indigenous research acknowledges a central tenet in Indigenous knowledge; the idea that knowledge is based on the association of the social and natural worlds and that such knowledge so acquired should be shared among all people for the betterment of humankind. The idea of knowledge through research being sold in the market place of ideas is alien to Indigenous research. Knowledge obtained through indigenous research methodologies cannot be appropriated by any one individual or body. Indigenous research also asks for recognition of the co-producers of knowledge. Local subjects are not just 'informants' or 
'sources of data'. Their communities are legitimate knowledge producers in terms of the source of data collection and the explanation/theorization of such data. In effect, Indigenous research does not work with a separation of the researcher and the research subject. Such a research approach helps create a "community of learners" among researchers and local participants in research, operating with shared responsibilities about the goal, purpose, ethics and values of social research.

Indigenous scholars in the Western academy must always be conscious and wary of being caught in the web of the colonial project. Researchers cannot take for granted but must ask the following questions: what constitutes scholarly academic research, what is 'good' research and how should such research be approached and pursued? As I argue in a forthcoming paper on 'The Black Scholar' (Dei, 2013b) we must understand the myriad readings and positionalities of the Indigenous researcher to ground critical scholarship in questions of ethical responsibility, social and community relevance and political change. In effect, the worth of an Indigenous scholar cannot simply be measured in the philosophical grounding of our work (research, writing, dialogues etc.); but also, in how such work offers a social and political corrective to our communities. Indigenous research methods and methodologies can be applied anywhere. However, Indigenous research is imperative if we want to understand Indigenous communities. Too often, as researchers we claim a "right" in a space to do research, where such "rights" are dangerously conceptualized as our property or entitlement; an idea of rights so removed from Indigenous cultures that scholarly pursuits carried out with this rationalization should be questioned. Personally, I have also had to struggle with coming to terms with what it means to be a 'scholar and researcher' in the Western academy, how we remain true to ourselves as Indigenous scholars and researchers, and not becoming preoccupied with continually seeking validation, legitimation and acceptance in the eyes of a truly White/Eurocentric academy (see Dei, 2013b). For one thing, I know that if we fail to speak out and act to transform our presence in the academy as a colonial and colonizing space, then we continue to sow the seeds of mistrust that our communities have come develop of our educational institutions. Through Indigenous research we ease this burden and open up the university and research as spaces where Indigenous peoples - too often ignored, denigrated and hurt -- may be heard, valued and even begin to heal.

\section{References}

Andreotti, V, C. Ahenakew and G. Cooper (2011). "Epistemological Pluralism: Ethical and Pedagogical Challenges in Higher Education." Unpublished paper. [forthcoming]. 
Batacharya, S. "Life in a Body: Counter-Hegemonic Understanding of Violence, Oppression, healing and embodiment Among Young South Asian Women.” Unpublished Ph.D dissertation, Ontario Institute for Studies in Education of the University of Toronto. OISE/UT.

Dei, G. J. S. 1999. "Knowledge and Politics of Social Change: The Implication of AntiRacism.” British Journal of Sociology of Education 20 (3):395-409.

Dei, G. J. S. 2011. “The Possibilities Of Research, Educational Programming And Training In Indigenous Knowledges In The Academy." Invited Address, First International Conference "Endogenous Development and Trans-Disciplinarity in Higher Education: Challenges for the Co-evolution of Mainstream and Endogenous Knowledge Traditions", Cochabamba, Bolivia, October 30 -November 3.

Dei, G. J. S. 2013a. “'Suahunu: The Trialectic Space.” Journal of Black Studies- [ in press].

Dei, G. J. S. 2013b. “The Black Scholar." Entry in "The Encylcopedia of African Cultural Herigage' [edited by Mwalimu J. Shujaa \& Kenya J. Shujaa. Thousand Oaks, Sage Publishers

Dei, G. J. S. and G. S. Johal 2005 [eds]. Critical Issues in Anti-Racist Research Methodologies. New York: Peter Lang.

Garroutte, E. M. (2003). Real Indians: Identity and the survival of Native America. Berkeley, CA: University of California Press.

Harding, S. (1993). Starting thought from women's lives: Eight resources for maximizing objectivity. Journal of Social Philosophy, 21 (2/3), 140-149.

Harding, S. (2004). A socially relevant philosophy of science? Resources from standpoint theory's controversiality. Hypatia, 19 (1), 25-47.

Khan, S. (2005). Reconfiguring the native informant: Positionality in the global age. Signs: Journal of Women in Culture and Society, 30 (4), 2017-2035.

Kovach, M. (2009). Indigenous Methodologies: Characteristics, Conversations, and Contexts. Toronto: University of Toronto Press. 
Litowitz, D.E. (2009). Some critical thoughts on critical race theory. In E. Taylor, D. Gillborn and G. Ladson-Billings (Eds.), Foundations of critical race theory in Education (pp. 291 - 310). New York: Routledge, Taylor \& Francis Group.

Longino, H. E. (1993). Feminist standpoint theory and the problems of knowledge. Signs: Journal of Women in Culture and Society, 19 (1), 201-212.

Loutzenheiser, L.W. (2007) Working alterity: The impossibility of ethical research with youth: Educational Studies, 41 (2), 108-127.

Oyewumi, O. 1997. The Invention of Women: The Making an African Sense of Western Gender Discourses. Minneapolis: University of Minnesota Press.

Radebe, P. (2012) “Comprehensive Exam \#2 Paper," Department of Educational Studies University of British Columbia, Vancouver, Canada.

Smith, D.E. (1993). High noon in textland: A critique of Clough. Sociological Quarterly, 34(1), 183-192.

Smith, D.E. (1997). Comment on Hekman's “Truth and methods: Feminist standpoint theory." Signs, 22 (2), 392-398.

Smith, L. 1999. Decolonizing Methodologies. London: Zed Books.

Swigonski, M.E. (1993). Feminist standpoint theory and the question of social work research. Affilia, 8 (2), 171-183.

Wilson, S. (2001). What is Indigenous research methodology? Canadian Journal of Native Education. 25 (2): 175-179.

Wilson, S. (2008). Research is Ceremony: Indigenous Research Methods. Halifax: Fernwood. 